\title{
Applying Innovation Diffusion Theory to Determine Motivating Attributes for Successful Implementation of Internet-Based Interventions for Evidence Based Medicine: a Developing Country Context
}

\author{
Fozia Anwar* \\ Faculty of Health Sciences, Higher Colleges of Technology, UEA \\ *Corresponding author: Fozia Anwar, Faculty of Health Sciences, Higher Colleges of Technology, UEA
}

\begin{abstract}
Current healthcare outcomes depend on the adoption of valid and latest research evidence and practicing evidence-based medicine (EBM). EBM is the process of adaptation of the finest available scientific research evidence into routine clinical practice. However, literature reports gap between actual and required clinical practice. This gap will not be bridged by just updating physicians about EBM. Therefore, it is required to study the motivational factors in a context to use technology in routine clinical practice as things behave differently under varying constraints. This study aimed to address this gap by investigating motivating factors to promote EBM, focusing mainly on developing country context. Innovation diffusion theory will be used to provide the basic or theoretical support for the research as this theory states that the adoption of any innovation is itself facilitated by its certain characteristics. Cross-sectional quantitative methodology will be used for this research. SPSS and SEM will be used to analyze data and validation of the tested research model. The innovation diffusion theory may provide constructive and practical insights into the factors for the successful implementation of EBM, as well as it will provide a guideline for those who try to adopt the bestevidences into their clinical practice.
\end{abstract}

Keywords: Innovation diffusion theory; Evidence based medicine; EBM; DOI Diffusion of innovation

\section{Introduction}

The innovation is a new idea that is observed by the individual. Evidence-based medicine is an innovation in the clinical decisionmaking process, which promises to improve health care delivery [1]. But at the same time, practicing EBM is a paradigm shift that is changing the conventional way of the clinical decision-making process [2]. Acceptance of any change or innovation in conventional clinical practices is always very hard, and multiple factors play their part in the adoption procedure [3]. The characteristics of innovation play a significant role in defining its rate of adoption [4]. For an innovation to be adopted, it must be perceived as offering relative advantage, i.e., simple, compatible, observable and testable. Roger proposes one of the theoretical approaches addressing the diffusion of innovation (DOI). DOI model is supportive at describing the acceptance of explicit clinical events, mostly when determining which components will need additional effort if diffusion is to ensure [4]. Literature showed applications of DOI in health departments as well [5-7]. Becker and Mohr worked to identify organizational characteristics linked with the diffusion process among the health department [6]. One study found that demographic features age, gender, education level, urban and rural areas had a great impact on the time for adoption of innovation. It was noted that the initial adopters of innovations different by age, education and used information-seeking approaches as compared to their jurisdictions who are varied by rurality $[7,8]$. Graduated younger people who had a higher standing in their graduating class and belonged to urban areas were ready to adopt less risky interventions. In comparison, older people in countryside areas who had a normal standing in their graduating class, and they 
established their leadership roles were ready to take more risks, but they adopt less conventional innovations. It is also evident in literature that large health departments easily adopt innovations than small health departments. The accessibility of funds and human resources are the reasons which are supporting this finding $[8,9]$.

The effective implementation of EBM in the healthcare sector, a better understanding of the motivating factors is required in detail. Relation and association of factors with each other are also very important as the context is very special, and physicians have autonomous authority in the clinical decision-making process. Context and users of technology matter a lot because things behave differently under varying constraints. It is evident from literature that the primary characteristics of the innovations have been conflicting as these are inherent in the innovation. These primary characteristics are not dependent on the perceived characteristics of the intended users. Augury of the potential user's behavior depends on their perception about the primary traits as different users may perceive the primary characteristics of the innovation in a different way, which can cause different behavior of the users. This is the origin of the problem of using the primary characteristics of innovation.

Innovation Diffusion Theory (IDT) is used for this research work because IDT is considered relevant and useful to researchers conducting studies of information systems innovations in healthcare organizations. The IDT theory tries to explain the diffusion of new ideas, attitudes, opinions, and behaviors all over a community. The

Table 1: Constructs with code and their hypothesized relation.
IDT is an important constituent of the upgrading health services worldwide, yet the literature illustrates that it is not always an easy theory to relate empirically [10]. IDT identifies five factors that influence the diffusion and adoption of an innovative idea or strategy. The IDT offers a theoretical framework globally to accept information technology. The role of ethnical background plays an important part in the adoption of new ideas/technology as it addresses that how, why, and what adoption rate of new technology can relate with different social backgrounds and settings [11]. IDT not only addresses the adoption of information technology only, but it also addresses other diffusion processes through the society, such as the acceptance of new technology products such as services, style of music, fashion, food, ideas, or political candidates [11-13].

This study builds upon what is known from past research on the diffusion and research conducted by Jenine K. Harris [8], which described the significance to comprehend how health personnel perceives the relative advantage, simplicity, compatibility, and testability of evidence-based decision making. Specifically, this research examined the effect of IDT factors, which can play a great motivational role for the physicians to adopt the new way of the clinical decision-making process. Results are based on their perceptions and experience of practicing EBM. Rogers identified five (05) elements of a new or substitute clinical behavior that can help in determining the adoption of a new activity such as EBM. These are relative advantage, compatibility, complexity, trialability, and observability [14]. Definitions of all these four elements are given in Table 1 along with the hypothesized relations. All these variables are discussed below.

\begin{tabular}{|c|c|c|c|}
\hline Constructs & Code & Definitions & Hypothesized Relation \\
\hline Relative advantage & RA & $\begin{array}{l}\text { "The degree to which an innovation is perceived as better } \\
\text { than using its precursors." [4] }\end{array}$ & RA UI \\
\hline Compatibility & $\mathrm{CM}$ & $\begin{array}{l}\text { "The degree to which an innovation is perceived as being } \\
\text { consistent with the existing values, past experiences, and } \\
\text { needs of potential adopters." [4] }\end{array}$ & CM UI \\
\hline Complexity/ Simplicity & SP & $\begin{array}{l}\text { "The degree to which an innovation is perceived as } \\
\text { difficult to understand and use." [4] }\end{array}$ & SP UI \\
\hline Trialability & TR & $\begin{array}{l}\text { "The degree to which an innovation may be experimented } \\
\text { with on a limited basis." [4] }\end{array}$ & TR UI \\
\hline $\begin{array}{l}\text { Observability to those people } \\
\text { within the social system }\end{array}$ & OB & $\begin{array}{c}\text { "The degree to which the results of an innovation are } \\
\text { visible to others." [4] }\end{array}$ & OB UI \\
\hline Usage Intention & UI & $\begin{array}{l}\text { The subjective probability that he or she will engage in a } \\
\text { given behavior [14] }\end{array}$ & Dependent Variable \\
\hline
\end{tabular}

\section{Independent variables}

Relative advantage: The social prestige, satisfaction and convenience, clinicians are some important factors for measuring the degree of relative advantage. Relative advantage can also be measured in economic terms for a new clinical activity [3]. Objective advantage of innovation is less important as compared to clinician's perception of the advantages of innovation. Clinicians, patients, and the healthcare system together decide the best-evidence practice implementation. For instance, if a new clinical activity changes the power distribution balance in professional groups in a negative way, then the innovation cannot be successfully applied. On the other hand, if the proposed activity generates more revenue and benefits 
the clinicians without disturbing the balance of power distribution, then innovation will be readily accepted and adopted.

Therefore, it is hypothesized that

H1: Relative advantage of EBM has a noteworthy positive effect on the usage intention for EBM adoption.

Compatibility: It is necessary for successful adoption of an innovation that it must tackle an issue that is perceived as problematic by the clinicians. For instance, a new clinical activity or procedure will be adopted fast if it helps clinicians to detect cancer or other life-threatening illness at very early stages [15]. It is a strong medical belief that early detection of a disease is beneficial for the patients. Accordingly, clinical activity or procedure offering this capacity will be adopted quickly. The rapid adoption of mammography screening [16,17] and testing for prostate cancer are a few real-life examples. Though literature also has some controversial debates about the therapy mentioned above effectiveness.

\section{Therefore, it is hypothesized that}

H2: Compatibility of EBM has a significant positive effect on the usage intention for EBM adoption.

Complexity/Simplicity: Literature proves that the probability of adoption for a clinical procedure increases when the procedure is simple, easy, and well defined. For example, the rate of change in drug regimen for patients by clinicians is high and the reason behind this phenomenon is that it is easy to adopt. While some precautionary activities as detecting and handling patients with harmful alcohol consumption [18] have not been adopted quickly, though reported potential health gain in literature. This may be due to the complexity of these activities. All preventions at the primary level are vulnerable due to the patient's resistance and their lack of accuracy in self-reporting risk behaviors. Additionally, inadequate expertise in the consulting skills of clinicians necessary to achieve change may be the other reason.

Therefore, it is hypothesized that

H3: Complexity/simplicity of EBM has a significant positive effect usage intention for EBM adoption.

Trialability: According to Rogers, "trialability" is the degree of modification of an innovation. In other words, the capability to test an intervention in medicine on a limited basis allows clinicians to explore the implementation of the procedure, its acceptability, and the possible outcomes. Rogers claims that the ability to undertake limited cost-benefit experiments of an intervention endorses trust and confidence that the evidence is not only, but its implementation is logistically promising as well.

Therefore, it is hypothesized that

H4: Trialability of EBM has a significant positive effect on the usage intention for EBM adoption.

Observability: Observability means the idea of innovation is visible to others. The visibility of innovation's results motivates colleagues to discuss that particular innovation. Discussions on the method or innovation by the influential physician will further enhance the adoption rate. More clinicians will tend to adopt the change in their clinical behavior if the role model practitioner is more influential and charismatic. New techniques are often adopted very quickly in the surgery department because of a common belief that there are disadvantages in being "left behind" by not adopting new technology.

Therefore, it is hypothesized that

H5: Observability of EBM has a significant positive effect on the usage intention for EBM adoption.

\section{Dependent variable}

UI: In IS research, the system usage intention is a vital construct. Self-reported usage is the only aspect of UI addressed by most of the researchers in quantitative studies. These studies adapted self-reported usage to operationalize the actual system usage, in the absence of usage metrics. In technology acceptance studies intentions leads towards behavior [19]. The reason behind this is high values of correlation reported in the literature for the relation of intention and behavior. This research framework focused on the use of UI as a dependent variable because the use of UI as a dependent variable has literature support relative advantage and compatibility equivalent to PEOU and PU constructs. Under conditions of incomplete volitional control, the intention cannot act as a sufficient predictor of the behavior [20]. Diagrammatic representation of the research framework along with dependent and independent variables is given as Figure 1. 


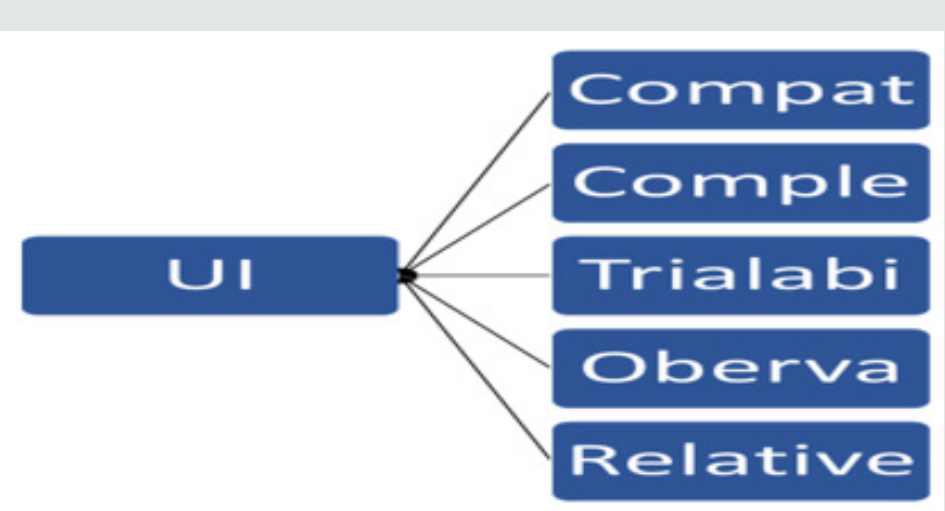

Figure 1: Research Model.

\section{Methodology}

\section{Sampling}

A simple random sampling method was used to collect data. Random numbers were generated through the computer after having access to the staff records of the physicians in the selected hospitals. The self-administered questionnaire used as a data collection tool. A description of the questionnaire is provided in the next section (Figure 2). A total of 350 questionnaires were distributed, and 290 responses were returned. Thus, the response rate was $82.85 \%$. Total of twenty responses was discarded due to the same reply, missing responses or left blank and thus the usable response rate was $77.1 \%$ of the 270 respondents, $61.1 \%$ were female doctors (Mean age $=38.3$ years, $\mathrm{SD}=10.7$ ) and $38.9 \%$ were male doctors (Mean age $=40.1$ years, $\mathrm{SD}=9.83$ ).

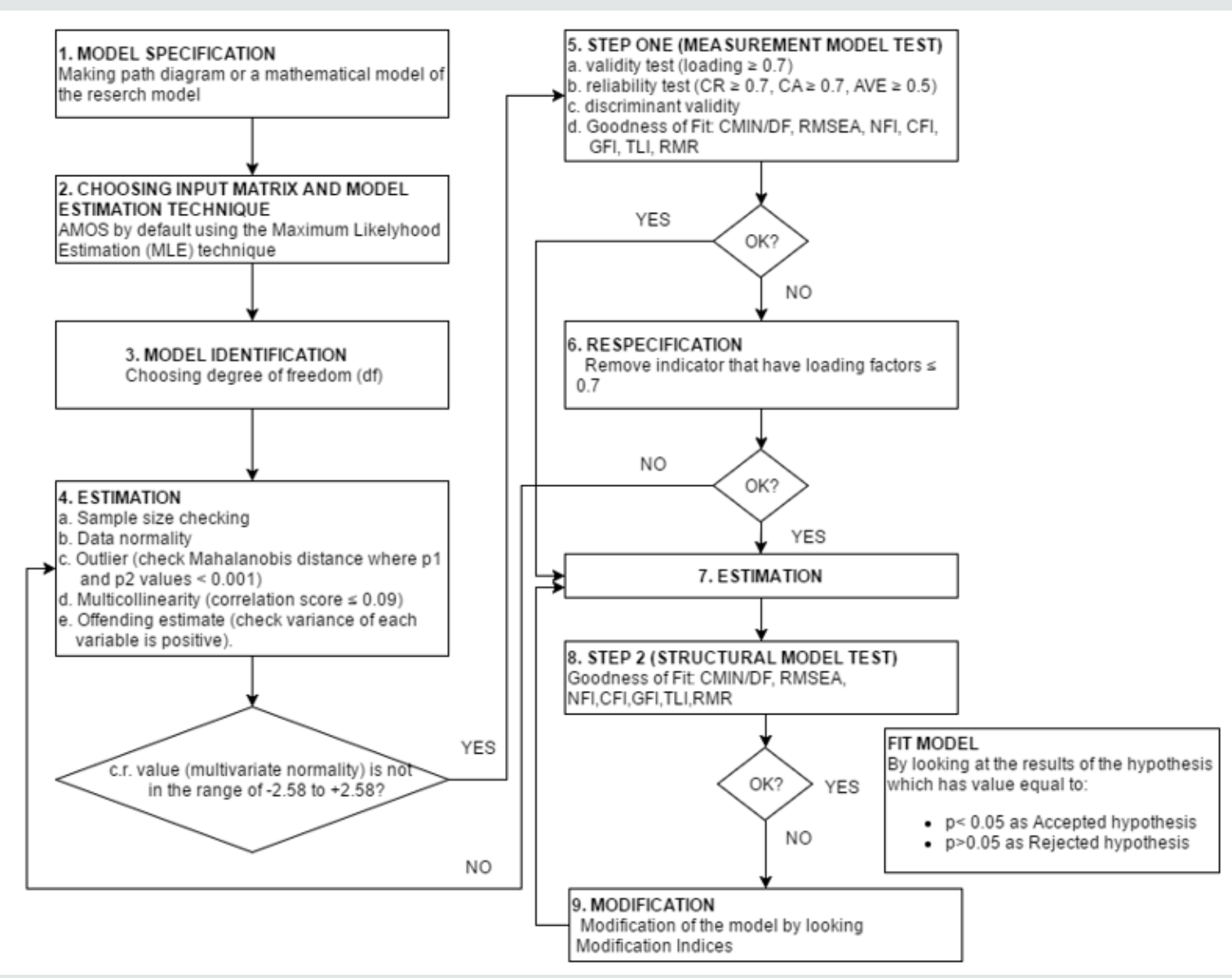

Figure 2: Model Specialization. 


\section{Data collection tool}

A structured close-ended questionnaire was used. At the beginning of the questionnaire definition of evidence-based medicine was provided to have a better understanding of the concept. Demographic questions (were age, gender, organization, and working experience) were included at the beginning of the questionnaire. It was requested to the participants to give feedback by thinking that practice evidence-based medicine will be a requirement in the future for their routine clinical practice. The standard variable for innovation diffusion theory (technical compatibility, simplicity, relative advantage, and intentions) was used in the current research model. The variables derived from other related studies on the extension of the IDT (Trialability and Observability) were also included to have a deeper understanding of the phenomenon. Seven (07) points Likert scale (1=strongly disagree, $7=$ strongly agree) was used to code the responses. English was the language of the questionnaire. All the constructs were measured through the validated items confirmed by the literature.

\section{Results and Discussion}

Table 2: Reliability of the constructs.

\begin{tabular}{|c|c|}
\hline Constructs & Alpha Value \\
\hline BI & 0.946 \\
\hline CM & 0.937 \\
\hline OB & 0.854 \\
\hline RA & 0.945 \\
\hline SP & 0.934 \\
\hline TR & 0.909 \\
\hline
\end{tabular}

Data screening was performed to identify missing data. The expectation-maximization technique was applied by using little's MCAR test, and it was found that the missing data was less than 10 percent, and it is missing completely at random. Missing data were handled by using the mean substitution imputation method. Skewness and kurtosis were checked to detect data normality at a univariate level while Kolmogorov Smirnov and Shapiro Wilks tests were performed to check multivariate normality. Results suggested that the data was normally distributed both at univariate and multivariate level. The linear regression method by using the Mahalanobis distance test was performed to detect the presence of outliers. Results revealed that the presence of the few outliers; it was, decided to retain all the cases, as there was insufficient evidence to suggest that these outliers were not part of the entire population (Hair et al. 2006). Construct reliability for each construct is calculated with alpha value and tabulated in Table 2 all values are within an acceptable range. After basic data screening process factor analysis is performed.

\section{Factor analysis (FA)}

FA is a multivariate regression analysis statistical method used to analyze the correlation structure between different variables/constructs. In FA, after identifying latent dimensions of the constructs, data reduction was performed. Exploratory factor analysis (EFA) and confirmatory factor analysis (CFA) are two steps in FA. The data is explored in EFA, while hypothesis is tested in CFA [21]. For the current analysis, the researcher performed both steps of factor analysis. EFA: There are two main steps in EFA, which are extraction and rotation processes. The extraction process identifies the underlying factors or constructs, while the rotation process yields an easy presentation of a factor loading pattern. In the current analysis, the researcher used the orthogonal rotation method for factor loading. Before performing factor analysis, we must check the suitability of current research data for sample adequacy. For this purpose, we performed KMO and Bartlett's Test.

\section{Kaiser-Meyer Olkin (KMO) and Bartlett's Test}

For the current research study, the value of the KMO test is 0.853 , which shows the confidence about sample size adequacy to proceed for further steps of factor analysis. The result for Bartlett's test can be interpreted on the value of significance. The value of significance is .000 confirmed that the analysis could continue by using factor analysis as tabulated in Table 3. Furthermore, for exploratory factor analysis (EFA), the principal components analysis (PCA) and orthogonal model with varimax rotation method were applied. The result of principal component analysis also confirms the presence of 6 factors explaining the total variance of the components as shown in Table 4. The results recommended the deletion of the item SP4 of Complexity/ Simplicity construct, as it was highly cross loaded on another latent factor, OB (observability). The graphical presentation of latent constructs based on eigenvalues in EFA is shown in the scree plot (Figure 3). Scree plot plots all the eigenvalues in their decreasing order, where eigenvalues on the vertical axis and factors on the horizontal axis. The scree plot confirms the choice of 6 components.

Table 3: KMO and Bartlett's test of sphericity.

\begin{tabular}{|c|c|c|}
\hline KMO and Bartlett's test & \\
\hline Kaiser-Meyer-Olkin Measure of Sampling Adequacy. & Approx. Chi-Square \\
\hline Bartlett's Test of Sphericity & Df & \\
\hline & 6941.519 & Significance \\
\hline
\end{tabular}


Table 4: Total Variance explained.

\begin{tabular}{|c|c|c|c|c|c|c|c|c|c|}
\hline Component & $\begin{array}{c}\text { Initial } \\
\text { Eigenvalues }\end{array}$ & & & $\begin{array}{c}\text { Extraction } \\
\text { Sums of } \\
\text { Squared } \\
\text { Loadings }\end{array}$ & & & $\begin{array}{c}\text { Rotation } \\
\text { Sums of } \\
\text { Squared } \\
\text { Loadings }\end{array}$ & & \\
\hline & Total & $\begin{array}{l}\text { Percentage } \\
\text { of Variance }\end{array}$ & $\begin{array}{l}\text { Cumulative } \\
\text { Percentage }\end{array}$ & Total & $\begin{array}{l}\text { Percentage } \\
\text { of Variance }\end{array}$ & $\begin{array}{l}\text { Cumulative } \\
\text { Percentage }\end{array}$ & Total & $\begin{array}{l}\text { Percentage } \\
\text { of Variance }\end{array}$ & $\begin{array}{l}\text { Cumulative } \\
\text { Percentage }\end{array}$ \\
\hline & & (\%) & (\%) & & (\%) & (\%) & & (\%) & (\%) \\
\hline 1 & 14 & 48.259 & 48.259 & 13.995 & 48.259 & 48.259 & 4.733 & 16.319 & 16.319 \\
\hline 2 & 2.25 & 7.759 & 56.018 & 2.25 & 7.759 & 56.018 & 4.618 & 15.924 & 32.243 \\
\hline 3 & 2.03 & 7 & 63.018 & 2.03 & 7 & 63.018 & 4.07 & 14.036 & 46.279 \\
\hline 4 & 1.82 & 6.263 & 69.281 & 1.816 & 6.263 & 69.281 & 3.961 & 13.659 & 59.938 \\
\hline 5 & 1.48 & 5.094 & 74.374 & 1.477 & 5.094 & 74.374 & 3.781 & 13.038 & 72.976 \\
\hline 6 & 1.4 & 4.811 & 79.185 & 1.395 & 4.811 & 79.185 & 1.801 & 6.209 & 79.185 \\
\hline 7 & 0.54 & 1.873 & 81.058 & & & & & & \\
\hline $\begin{array}{l}\text { Extraction } \\
\text { Method: } \\
\text { Principal } \\
\text { Component } \\
\text { Analysis. }\end{array}$ & & & & & & & & & \\
\hline
\end{tabular}

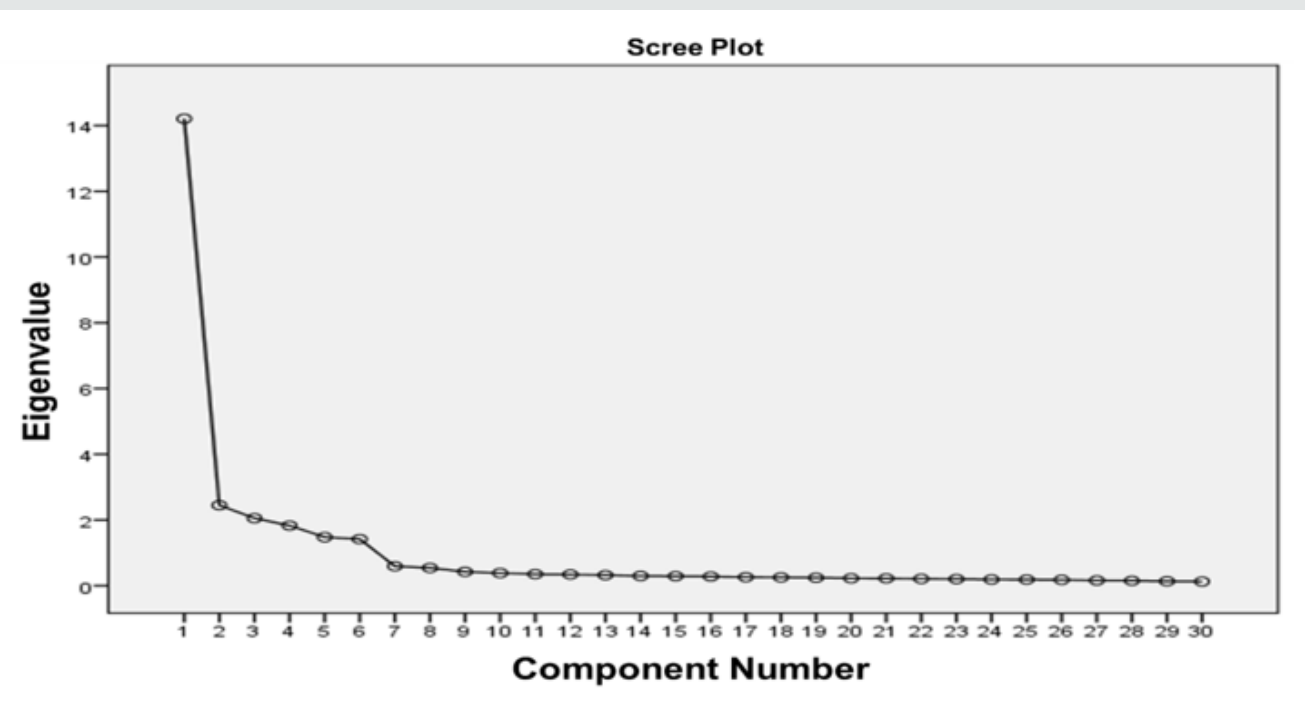

Figure 3: Scree plot representing the eigenvalues.

\section{Confirmatory factor analysis (CFA)}

CFA consists of the measurement and structural model. The measurement model used to evaluate the model validity and reliability. The reliability includes Cronbach's alpha, while validity includes discriminant validity. Whereas structural model is used to test the relationship between constructs. The result for discriminant validity is shown in Table 5. The off-diagonal values represents correlation squared while diagonal values represent AVE In order to meet the criteria for discriminant validity, it is required that the AVE square root for each construct should be greater than the interconstruct correlation as tabulated in Table 6. It is also found that the inter-construct correlation value was not above the square-root of the AVE, so the model satisfies the discriminant validity criterion. In Table 7, the fit indexes for both measurement and structural model are given. Hypothesis testing is done by using the structural model. It is noted that four out of five hypotheses are supported either at .001 (***) or .05 level of p-value; only one hypothesis BIOOB is rejected. Path diagram showing all the hypothesis is presented in Figure 4 . The most probable reason for the insignificant hypothesis between observability and usage intention was that the software and information system had less observability by physicians, hence less rate of adoption as compare to hardware innovation [22]. Consequently, the more potential user can see the innovation, the more likely he will adopt it. 


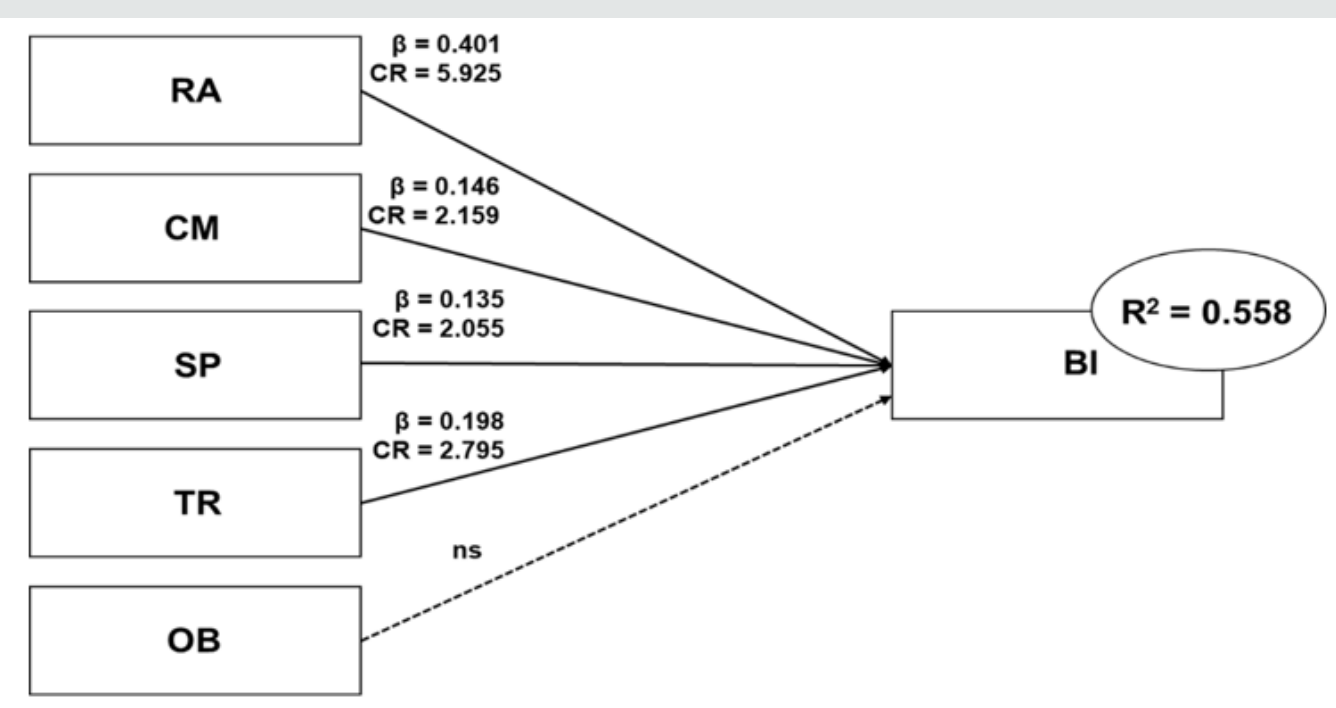

Figure 4: Path Diagram.

Table 5: Discriminant Validity.

\begin{tabular}{|c|c|c|c|c|c|c|}
\hline Correlations Squared & OB & RA & SP & CM & TR & BI \\
\hline OB & 0.865 & & & & & \\
\hline RA & 0.335 & 0.861 & & & & \\
\hline SP & 0.41 & 0.566 & 0.86 & & \\
\hline CM & 0.338 & 0.638 & 0.567 & 0.844 & & \\
\hline TR & 0.291 & 0.573 & 0.585 & 0.6 & 0.818 & \\
\hline BI & 0.344 & 0.7 & 0.579 & 0.609 & 0.589 & 0.883 \\
\hline
\end{tabular}

Table 6: Hypotheses testing.

\begin{tabular}{|c|c|c|c|c|c|c|}
\hline Constructs & Code & Hypothesis & Relationships & P-value & $\boldsymbol{\beta}$ Value & Status \\
\hline RA & RA & H1 & BIßRA & $* * *$ & 0.401 & Supported \\
\hline CM & CM & H2 & BIßCM & $*$ & 0.146 & Supported \\
\hline SP & SP & H3 & BIßSP & $*$ & 0.135 & Supported \\
\hline TR & TR & H4 & BIßTR & $* *$ & Supported \\
\hline OB & OB & H5 & BIßOB & & 0.042 & Rejected \\
\hline
\end{tabular}

Table 7: Fit indexes for Measurement model and structure model.

\begin{tabular}{|c|c|c|c|c|c|c|c|c|}
\hline $\begin{array}{c}\text { Absolute fit } \\
\text { measure }\end{array}$ & & & & & & & $\begin{array}{c}\text { Parsimonious fit } \\
\text { measure }\end{array}$ & $\begin{array}{c}\text { Incremental } \\
\text { fit measure }\end{array}$ \\
\hline Acceptable fit & & Df & CMIN/Df & GFI & RMSEA & AGFI & CFI & NFI \\
\hline $\begin{array}{c}\text { Obtained fit } \\
\text { MM }\end{array}$ & 437.573 & 356 & 1.229 & 0.899 & 0.029 & 0.876 & 0.988 & 0.939 \\
\hline $\begin{array}{c}\text { Obtained fit } \\
\text { SM }\end{array}$ & 456.46 & 357 & 1.279 & 0.896 & 0.032 & 0.873 & 0.985 & 0.937 \\
\hline
\end{tabular}




\section{Limitation}

This study has following limitations:

a) Cross-sectional self-reported data limit this study.

b) Only one healthcare system, which might not reflect the factors for the successful diffusion of EBM in other health care settings.

c) Using an anonymous survey for data collection.

d) The small sample sizes.

\section{Limitations of SEM include}

a) The use of a model development process to improve goodness of fit, which is sometimes referred to as a "post hoc" procedure for hypothesis formulation.

b) The use of goodness-of-fit measures to accept or reject a proposed model. These measures can inform the researcher whether a model is acceptable but cannot tell whether it is a superior model. Since in SEM the complete set is required for analysis, therefore imputing missing data could affect the analysis.

\section{Conclusion}

Evidence-based medicine holds promise in improving health care quality and efficacy by improving the clinical decision-making process. So far, health care is decades behind other industries to adoption and use of information technology (IT). Though, stakeholders in the health care sector have highlighted the urgent need to adopt IT systems. This research work advocates that the resources presently accessible to practice EBM are unlikely to attain full diffusion in the preferred time frames. Regardless of the existing resources, the factors influencing adoption patterns are also unlikely to change absent significant incentives that have a positive impact on the new paradigm of clinical practice. Already a lot of time elapsed between the introduction of sustainable EBM technologies and today. There is growing recognition that the EBM diffusion process is multidimensional and that no single dimension will effectively address all the barriers and challenges to EBM adoption by physicians. Future research that draws on cross-national comparisons of government programs and their effect on diffusion factors could help shape policy maker's attempts to accelerate EBM adoption among health providers. It would be informative to have in-depth information on how physicians and other providers react to the government-introduced standards.

\section{References}

1. Kaminski J (2011) Diffusion of innovation theory. Canadian Journal of Nursing Informatics 6:1-6.
2. Lambert H (2006) Accounting for EBM: notions of evidence in medicine. Soc Sci Med 62(11):2633-2645.

3. Sanson Fisher RW (2004) Diffusion of innovation theory for clinical change. Med J Aust 180(S6):S55-S56.

4. Rogers EM (2010) Diffusion of innovations: Simon and Schuster.

5. Becker MH (1970) Sociometric location and innovativeness: Reformulation and extension of the diffusion model. American Sociological Review 35(2):267-282.

6. Mohr LB (1969) Determinants of innovation in organizations. American political science review 63:111-126.

7. Becker MH (1970) Factors affecting diffusion of innovations among health professionals. American Am J Public Health Nations Health 60(2):294-304.

8. Harris JK, Erwin PC, Smith C, Brownson RC (2015) The diffusion of evidence-based decision making among local health department practitioners in the United States. J Public Health Manag Prac 21(2):134140 .

9. Jardim JB (2008) Diffusion of innovations in health service organisations: a systematic literature review. Cadernos de Saúde Pública 24:14561457.

10. Valente TW, Fosados R (2006) Diffusion of innovations and network segmentation: the part played by people in promoting health. Sex Transm Dis 33(7 Suppl): S23-S31.

11. Rogers EM (2003) Elements of diffusion. Diffusion of innovations 10:138.

12. Rogers Everett M (1995) Diffusion of innovations, New York p.12.

13. Rogers EM (2004) A prospective and retrospective look at the diffusion model. J Health Commun 9(Supply 1):13-19.

14. Fishbein M, Cappella JN (2006) The role of theory in developing effective health communications. Journal of communication 56(s1): S1-S17.

15. McMullen H, Griffiths C, Leber W, Greenhalgh T (2015) Explaining high and low performers in complex intervention trials: a new model based on diffusion of innovations theory. Trials 16: 240-242.

16. Wang F, Zhang S, Henderson LM (2018) Adaptive decision-making of breast cancer mammography screening: A heuristic-based regression model. Omega 76: 70-84.

17. Mottet N, Bellmunt J, Bolla M, Briers E, Cumberbatch MG, et al. (2017) EAU-ESTRO-SIOG guidelines on prostate cancer. Part 1: screening, diagnosis, and local treatment with curative intent. Eur Urol 71(4):618629.

18. Schorling JB, Klas PT, Willems JP, Everett AS (1994) Addressing alcohol use among primary care patients. Journal of general internal medicine 9:248-254.

19. Mathieson K, Peacock E, Chin WW (2001) Extending the technology acceptance model: the influence of perceived user resources. ACM SigMIS Database 32:86-112.

20. Fishbein M, Ajzen I (1975) Belief, attitude, intention and behavior: An introduction to theory and research.

21. Joseph F BB (2006) Hair, Barry Babin, Rolph E. Anderson, Ronald L. Tatham, Multivariate Data Analysis ( $6^{\text {th }}$ Edn.) [Hardcover] Prentice Hall, USA.

22. Moore GC, Benbasat I (1991) Development of an instrument to measure the perceptions of adopting an information technology innovation. Information systems research 2:192-222. 


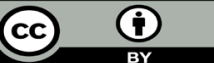

This work is licensed under Creative Commons Attribution 4.0 License

To Submit Your Article Click Here:

Submit Article

DOI: $10.32474 /$ SJPBS.2020.04.000187

\begin{tabular}{|c|c|}
\hline SJPBS & $\begin{array}{l}\text { Scholarly Journal of Psychology } \\
\text { and Behavioral Sciences }\end{array}$ \\
\hline 5 & $\begin{array}{l}\text { Assets of Publishing with us } \\
\text { - } \quad \text { Global archiving of articles } \\
\text { - Immediate, unrestricted online access } \\
\text { - } \quad \text { Rigorous Peer Review Process }\end{array}$ \\
\hline $\begin{array}{l}\text { Scholarly Journal of } \\
\text { Pschology \& Behavioral sciences }\end{array}$ & $\begin{array}{l}\text { - Authors Retain Copyrights } \\
\text { - Unique DOI for all articles }\end{array}$ \\
\hline
\end{tabular}

